\title{
Functionalization of Single-Walled Carbon Nanotubes and Fullerenes via A Zwitterion Approach
}

\author{
Wei Zhang and Timothy M. Swager* \\ Department of Chemistry and Institute for Soldier Nanotechnologies, Massachusetts \\ Institute of Technology, Cambridge, Massachusetts 02139, USA
}

Materials: Raw (HiPCO) SWCNTs, received from Carbon Nanotechnologies Inc. (CNI lot\# R0204), were further purified by exposure to air at $300{ }^{\circ} \mathrm{C}$ followed by conc. $\mathrm{HCl}$ wash to remove remaining metal catalysts before use. Fullerenes $(99.5 \%)$ were obtained from Alfa Aesar and used as received. All solvents were of spectroscopic grade unless otherwise noted. Anhydrous toluene, dichloromethane, acetonitrile, and tetrahydrofuran were obtained using a solvent purification system (Innovative Technologies). All other chemicals were of reagent grade and used as received.

General Methods and Instrumentation: Nuclear Magnetic Resonance (NMR) spectra were recorded on Inova-500 NMR Spectrometer. Chemical shifts are referenced to residual solvent. Mass Spectra were obtained on Bruker Omniflex MALDI-TOF instrument. Raman spectra were measured on a Kaiser Hololab 5000R Raman Spectrometer using the excitation wavelength of $785 \mathrm{~nm}$. The spectra in the UV-Vis-NIR range were obtained using a Cary 6000i UV-vis-NIR spectrometer. TGA analyses were performed with a TGA Q50 apparatus (TA instruments). Experiments were carried out under nitrogen. Samples were heated at $5{ }^{\circ} \mathrm{C} / \mathrm{min}$ from $30{ }^{\circ} \mathrm{C}$ to $800{ }^{\circ} \mathrm{C}$. X-ray crystallographic data was collected on a Siemens Platform three-circle diffractometer coupled to a Bruker-AXS Smart Apex CCD detector. All synthetic manipulations were 
carried out under an argon atmosphere using standard Schlenk techniques unless otherwise noted. Glassware was oven-baked and cooled under $\mathrm{N}_{2}$ atmosphere.

Synthesis of Fullerene Derivative 3: A mixture of $\mathrm{C}_{60}(10 \mathrm{mg}, 0.014 \mathrm{mmol})$ and DMAP (4.4 $\mathrm{mg}, 0.036 \mathrm{mmol})$ in toluene $(6 \mathrm{~mL})$ in a $25-\mathrm{mL}$ Schlenk tube was sonicated using an ultrasonic bath (Branson 2510, $20 \mathrm{~W}, 42 \mathrm{kHz}$ ) until a homogeneous violet solution was obtained. To the resulting mixture was injected a solution of DMAD $(3.4 \mu \mathrm{L}, 0.028$ mmol $)$ in toluene $(0.5 \mathrm{~mL})$ dropwise. After addition, the system was stirred at room temperature for $0.5 \mathrm{~h}$ followed by the addition of methanol $(0.5 \mathrm{~mL})$. The resulting mixture was further stirred for another $2 \mathrm{~h}$. The solution was concentrated and the residue was subjected to column chromatography. The product was obtained as a red solid (8.1 $\mathrm{mg}, 68 \%)$. Fullerene recovered (1.9 mg, 19\%). ${ }^{1} \mathrm{H} \mathrm{NMR}\left(500 \mathrm{MHz}, \mathrm{CDCl}_{3} / \mathrm{CS}_{2}=2 / 1\right): \delta$ $=4.02\left(\mathrm{~s}, 3 \mathrm{H},-\mathrm{CO}_{2} \mathrm{CH}_{3}\right), 4.58\left(\mathrm{~s}, 3 \mathrm{H},-\mathrm{OCH}_{3}\right) ;{ }^{13} \mathrm{C} \mathrm{NMR}\left(125 \mathrm{MHz}, \mathrm{CDCl}_{3} / \mathrm{CS}_{2}, 2 / 1\right): \delta$ $=52.46,59.64,135.73,136.00,139.40,140.62,141.32,141.67,141.80,142.05,142.35$, $142.37,142.76,142.79,143.00,144.39,144.55,145.38,145.42,145.46,145.63,145.69$, 146.11, 146.21, 146.46, 146.54, 147.11, 147.17, 147.20, 147.43, 151.23, 152.87, 156. 62, $192.48\left(\mathrm{CS}_{2}\right)$; MALDI-TOF-MS: $\mathrm{m} / \mathrm{z}\left[\mathrm{M}^{+}\right]$calcd for $\left(\mathrm{C}_{66} \mathrm{H}_{6} \mathrm{O}_{4}\right)$ : 862.02, found: 861.95. $R_{f}=0.55\left(\mathrm{TLC}, \mathrm{SiO}_{2}\right.$, toluene $)$.

Synthesis of Fullerene Derivative 4: A mixture of $\mathrm{C}_{60}(10 \mathrm{mg}, 0.014 \mathrm{mmol})$ and DMAP (4.4 $\mathrm{mg}, 0.036 \mathrm{mmol})$ in toluene $(6 \mathrm{~mL})$ in a $25-\mathrm{mL}$ Schlenk tube was sonicated using an ultrasonic bath until a homogeneous violet solution was obtained. To the resulting mixture was injected a solution of DMAD $(3.4 \mu \mathrm{L}, 0.028 \mathrm{mmol})$ in toluene $(0.5 \mathrm{~mL})$ 
dropwise. After addition, the system was stirred at room temperature for $0.5 \mathrm{~h}$ followed by the addition of 2-methoxyethanol $(0.5 \mathrm{~mL})$. The resulting mixture was further stirred for another $2 \mathrm{~h}$. The solution was concentrated and the residue was subjected to column chromatography. The product was obtained as a red solid $(7.7 \mathrm{mg}, 62 \%)$. Fullerene recovered (2.1 mg, 21\%). ${ }^{1} \mathrm{H}$ NMR $\left(500 \mathrm{MHz}, \mathrm{CDCl}_{3} / \mathrm{CS}_{2}=2 / 1\right): \delta=3.55(\mathrm{~s}, 3 \mathrm{H},-$ $\left.\mathrm{OCH}_{2} \mathrm{CH}_{2} \mathrm{OCH} \mathrm{CH}_{3}\right), 3.94\left(\mathrm{~m}, 2 \mathrm{H},-\mathrm{OCH}_{2} \mathrm{CH}_{2} \mathrm{OCH}_{3}\right), 4.02\left(\mathrm{~s}, 3 \mathrm{H},-\mathrm{CO}_{2} \mathrm{CH}_{3}\right), 5.07(\mathrm{~m}, 2 \mathrm{H},-$ $\left.\mathrm{OCH}_{2} \mathrm{CH}_{2} \mathrm{OCH}_{3}\right) ;{ }^{13} \mathrm{C} \mathrm{NMR}\left(125 \mathrm{MHz}, \mathrm{CDCl}_{3} / \mathrm{CS}_{2}, 2 / 1\right): \delta=52.57,59.30,71.08,72.27$, $135.77,136.10,139.42,140.72,141.41,141.74,141.89,142.11,142.44,142.45,142.84$, $142.86,143.07,144.48,144.63,145.46,145.50,145.51,145.74,145.76,146.18,146.29$, 146.54, 146.62, 147.22, 147.25, 147.37, 147.52, 151.40, 153.05, 157.66, $192.57\left(\mathrm{CS}_{2}\right)$; MALDI-TOF-MS: $\mathrm{m} / \mathrm{z}\left[\mathrm{M}^{+}\right]$calcd for $\left(\mathrm{C}_{68} \mathrm{H}_{10} \mathrm{O}_{5}\right): 906.05$, found: 906.03. $R_{f}=0.69$ $\left(\mathrm{TLC}, \mathrm{SiO}_{2}\right.$, ethyl acetate/toluene $\left.=1 / 9\right)$.

Synthesis of SWCNT Derivative 5: A suspension of purified SWCNTs (4.0 mg, 0.33 mmol of carbon) in THF ( $40 \mathrm{~mL})$ was sonicated for 3 min using an ultrasonic probe (Branson Sonifier 450, $60 \mathrm{~W}, 20 \mathrm{kHz}$ ). The heterogeneous solution was heated at $60{ }^{\circ} \mathrm{C}$. To the SWCNT suspension were added simultaneously a solution of dimethyl acetylenedicarboxylate $(0.51 \mathrm{~mL}, 4.2 \mathrm{mmol})$ in THF $(10 \mathrm{~mL})$ and a solution of 4dimethylaminopyridine $(0.51 \mathrm{~g}, 4.2 \mathrm{mmol})$ in THF $(10 \mathrm{~mL})$ via syringe pump within $36 \mathrm{~h}$. To the reaction mixture was added methanol $(5 \mathrm{~mL})$. The resulting mixture was stirred at $60{ }^{\circ} \mathrm{C}$ for another $12 \mathrm{~h}$. The reaction mixture was cooled to room temperature, then centrifuged at $5000 \mathrm{rpm}$ for $5 \mathrm{~min}$. The supernatant was discarded and the residue was dispersed in DMF for 5 min using an ultrasonic bath. The mixture was centrifuged (5000 
rpm, $5 \mathrm{~min}$ ) and the supernatant was discarded. The same sequence was repeated twice with DMF and acetone used as solvents. Functionalized SWCNTs (5) were dried under vacuum overnight. See Figure 1, Figure S1 for characterization data.

Synthesis of SWCNT Derivative 6: A suspension of purified SWCNTs (4.0 mg, 0.33 mmol of carbon) in THF (40 mL) was sonicated for 3 min using an ultrasonic probe (Branson Sonifier 450, $60 \mathrm{~W}, 20 \mathrm{kHz}$ ). The heterogeneous solution was heated at $60{ }^{\circ} \mathrm{C}$. To the SWCNT suspension were added simultaneously a solution of dimethyl acetylenedicarboxylate $(0.51 \mathrm{~mL}, 4.2 \mathrm{mmol})$ in THF $(10 \mathrm{~mL})$ and a solution of 4dimethylaminopyridine $(0.51 \mathrm{~g}, 4.2 \mathrm{mmol})$ in THF $(10 \mathrm{~mL})$ via syringe pump within $36 \mathrm{~h}$. To the reaction mixture was added 1-dodecanol $(5 \mathrm{~g})$. The resulting mixture was stirred at $60{ }^{\circ} \mathrm{C}$ for another $12 \mathrm{~h}$. The reaction mixture was cooled to room temperature, then centrifuged at $5000 \mathrm{rpm}$ for $5 \mathrm{~min}$. The supernatant was discarded and the residue was dispersed in DMF for 5 min using an ultrasonic bath. The mixture was centrifuged (5000 $\mathrm{rpm}, 5 \mathrm{~min}$ ) and the supernatant was discarded. The same sequence was repeated twice with DMF and acetone used as solvents. Functionalized SWCNTs (6) were dried under vacuum overnight. 


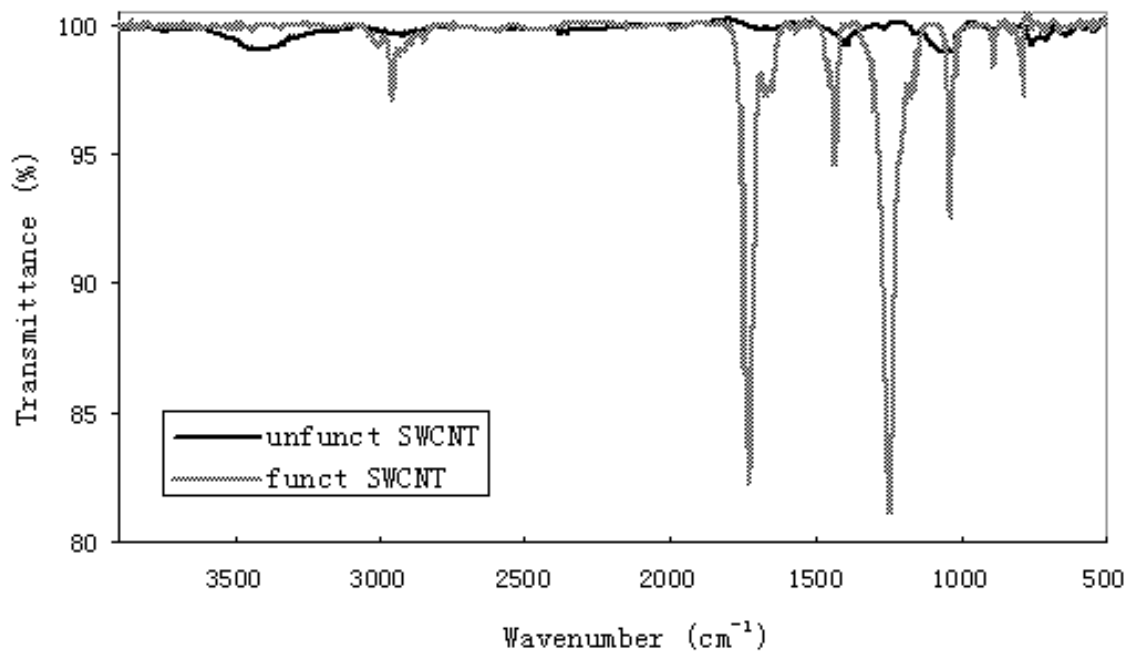

Figure S1. IR of pristine SWCNTs and functionalized SWCNTs 5.

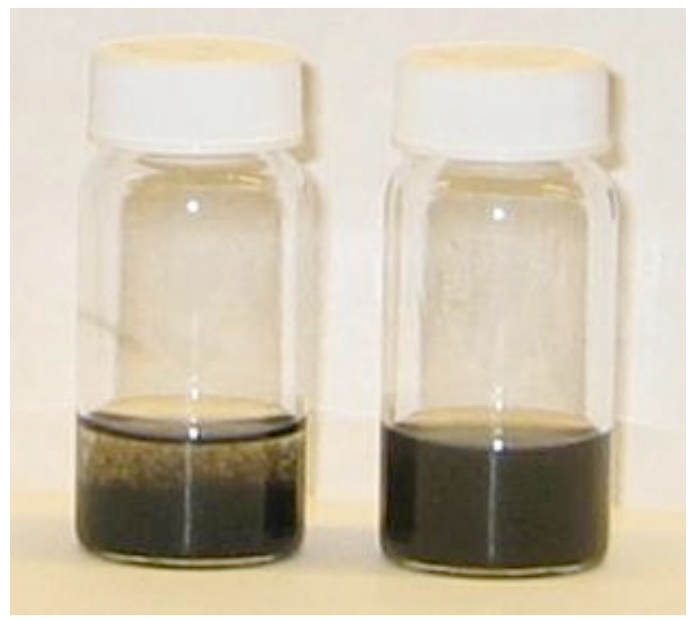

Figure S2. Dispersion of methoxy-functionalized SWCNT 5 (left, $3.2 \mathrm{mg}$ in $8.0 \mathrm{~mL}$ of THF) vs. dispersion of dodecyloxy-functionalized SWCNT 6 (right, $3.4 \mathrm{mg}$ in $8.0 \mathrm{~mL}$ of THF). Pictures were taken $5 \mathrm{~min}$ after sonication. 


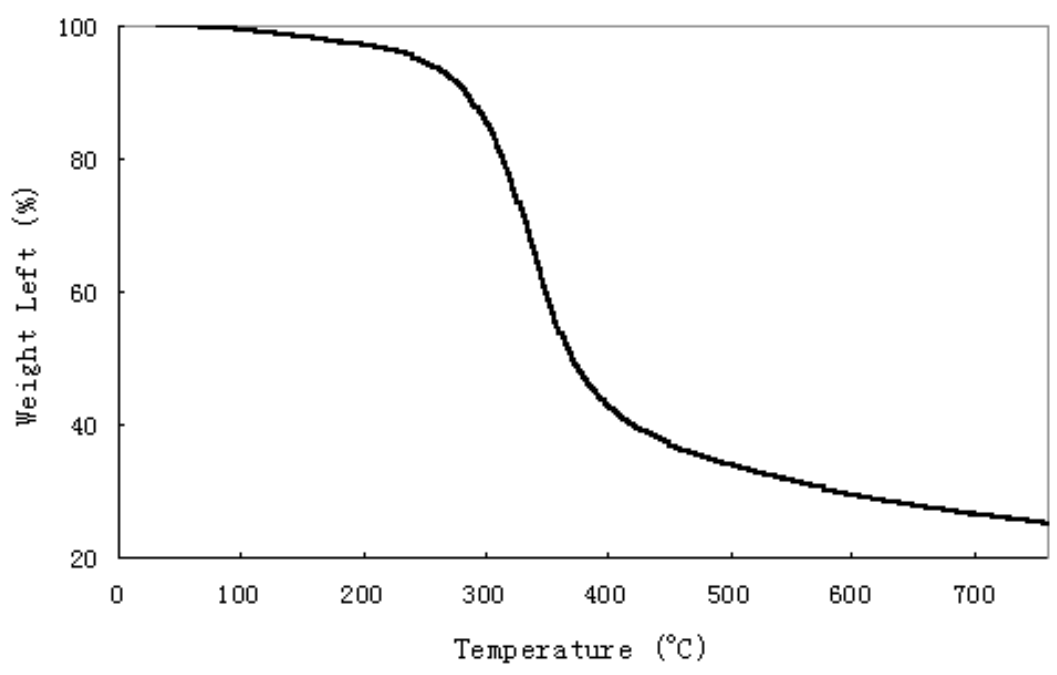

Figure S3. TGA of dodecyl functionalized SWCNT 6.

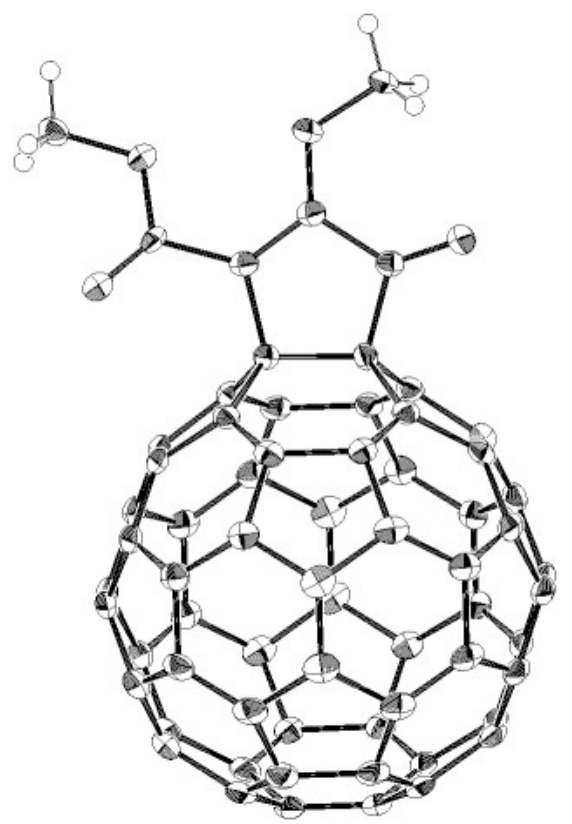

Figure S4. Crystal structure of fullerene derivative 3. A solvating $\mathrm{CS}_{2}$ molecule is omitted for clarity.

X-ray crystallographic data of fullerene derivative 3: Compound 3 was crystallized from a mixed solvent of $\mathrm{CHCl}_{3}$ and $\mathrm{CS}_{2}(1 / 1, \mathrm{v} / \mathrm{v})$. A $\mathrm{CS}_{2}$ molecule was co-crystallized with $\mathbf{3}$ and it was omitted in Scheme 1 and Figure S4 for clarity. X-ray data for $3 \bullet \mathrm{CS}_{2}$ 
$\left(\mathrm{C}_{67} \mathrm{H}_{6} \mathrm{O}_{4} \mathrm{~S}_{2}, M_{\mathrm{r}}=938.914\right):$ black plate, space group $P-1, a=9.9162, b=12.3631, c=$ 15.3130 $\AA, \alpha=89.386, \beta=84.283, \gamma=69.609^{\circ}, V=1750.33 \AA^{3}, Z=2, \rho_{\text {calcd }}=1.78$ $\mathrm{g} / \mathrm{cm}^{3}$, radiation: $\mathrm{Mo}_{\mathrm{K}_{\alpha}}=0.71073 \AA, T=100 \mathrm{~K}$. All non-hydrogen atoms were refined anisotropically. The hydrogen atoms were included in the model at geometrically calculated positions and refined using a riding model. $R_{1}=0.070, w R_{2}=0.188, \mathrm{GOF}=$ 1.051. 